\title{
Flavonoid mediated selective cross-talk between plants and beneficial soil microbiome
}

\author{
Sagar Bag • Anupam Mondal · Anusha Majumder $\cdot$ Sunil Kanti Mondal • \\ Avishek Banik
}

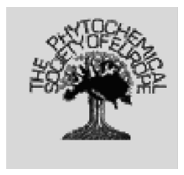

(2)

Received: 22 May 2021 / Accepted: 17 January 2022/Published online: 21 February 2022

(C) The Author(s), under exclusive licence to Springer Nature B.V. 2022

\begin{abstract}
Plants generate a wide variety of organic components during their different growth phases. The majority of those compounds have been classified as primary and secondary metabolites. Secondary metabolites are essential in plants' adaptation to new changing environments and in managing several biotic and abiotic stress. It also invests some of its photosynthesized carbon as secondary metabolites to establish a mutual relationship with soil microorganisms in that specific niche. As soil harbors both pathogenic and beneficial microorganisms, it is essential to identify some specific metabolites that can discriminate beneficial and pathogenic ones. Thus, a detailed understanding of metabolite's architectures that interact with beneficial microorganisms could open a new horizon of ecology and agricultural research. Flavonoids are used as classic examples of secondary
\end{abstract}

Supplementary Information The online version contains supplementary material available at https://doi.org/10.1007/ s11101-022-09806-3.

S. Bag · A. Mondal · A. Majumder · A. Banik ( $\square)$ Laboratory of Microbial Interaction, School of Biotechnology, Presidency University, Canal Bank Road, DG Block (Newtown), Action Area 1D, Newtown, Kolkata, West Bengal 700156, India e-mail: avishekbanik5@gmail.com; avishek.dbs@presiuniv.ac.in

S. K. Mondal

Department of Biotechnology, The University of

Burdwan, Burdwan, West Bengal, India metabolites in this study to demonstrate recent developments in understanding and realizing how these valuable metabolites can be controlled at different levels. Most of the research was focused on plant flavonoids, which shield the host plant against competitors or predators, as well as having other ecological implications. Thus, in the present review, our goal is to cover a wide range of functional and signalling activities of secondary metabolites especially, flavonoids mediated selective cross-talk between plant and its beneficial soil microbiome. Here, we have summarized recent advances in understanding the interactions between plant species and their rhizosphere microbiomes through root exudates (flavonoids), with a focus on how these exudates facilitate rhizospheric associations.

Keywords Secondary metabolites · Flavonoids · Quorum sensing · NodD-flavonoid complex · Plantmicrobe interactions

\section{Introduction}

During different growth phases, plants exudate a wide range of metabolites through its root. These root exudates act as the prime inducer to attract the autochthonous microbes thriving in that specific niche (Pascale et al. 2020). Additionally, these metabolites 
simultaneously attract both beneficial and pathogen microorganisms, as they can serve as the "sole source of energy" in nutritionally poor soils. Some of the compounds have also been involved in performing a crucial role in various interactions. While the structures of these exuded compounds differ greatly in complexity and size, most of them are generated from a small number of key biosynthetic pathways. The majority of these products are defined as the "secondary metabolites", which differentiate themselves from "primary metabolites", as it needed for plant growth and development. Secondary metabolites of plants can be generally categorized into three major groups of chemical substances; namely alkaloids, terpenoids, and phenolic compounds. Almost all of these large groups consisting of several thousands of separate individual compounds (Rai et al. 2017). This enormous variation in the function and composition of secondary metabolites emerges through numerous multiple substitutions/modifications of the common framework due to biochemical processes, such as methylation, hydroxylation, and glycosylation (Saito et al. 2013). The accumulation and biosynthesis of these secondary metabolites are condition and tissuespecific (Sweetlove and Fernie 2013).

Flavonoids are one of the broadest and bestcharacterized groups of plant secondary metabolites (PSM) and more than 8000 flavonoid compounds have now been identified and isolated from plants (Carazzone et al. 2013; Taneja et al. 2013; Xiao and Kai 2012). The prime network of flavonoid biosynthetic pathways is widely conserved throughout land plant species (Fernie 2019) and comprises routes for which enzymes and genes they encode have also been well characterized. Flavonoids are mainly generated from malonyl-CoA and amino acid phenylalanine and are consisting of a typical diphenylpropane backbone with two aromatic ring-like structures attached via a 3 -carbon chain (Tohge and Fernie 2017). Flavonoids are produced in the cytoplasm and for storage and other functional purposes, they are transported to vacuoles. Biological activities and functional characterization of different flavonoid transporters in plants have been well documented (Zhao 2015). Flavonoids are also commonly distributed in our regular diet and are important constituents of some common foodstuffs, like fruits, cocoa, tea, and vegetables. Nowadays, they are also regarded as an essential component in a diverse array of medicinal, pharmaceutical nutraceutical, and cosmetic applications (Tohge et al. 2017; Bag et al. 2022a). This is due to their anti-mutagenic, anti-oxidative, anti-carcinogenic and anti-inflammatory properties combined with their ability to modulate essential cellular enzymatic mechanisms (Panche et al. 2016; Xiao 2017; Bag et al. 2022b).

The relationships between both the plants and their surrounding microorganisms can be multifarious and the beneficial impact of those microbes on plant growth and development can be either indirectly, e.g. by modulating the activity of several genes in host plants (Pinedo et al. 2015) or directly, e.g. through the generation of different phytohormones, prevention of pathogenic growth and regulation of ethylene concentrations in plants (Mitter et al. 2013). Plants exudate different chemical signals into the rhizosphere which plays a crucial role to attract beneficial soil microbiome which protects them against biotic (infectious pathogenic agents) and abiotic stress (metal) (Neal et al. 2012; Huang et al. 2014; Chandra and Banik 2021). Numerous investigations have shown that most plants can shape and drive microbial selection by root secreting particular chemical compounds that enrich the specific microbial community in the rhizosphere (Bakker et al. 2012; Chaparro et al. 2012; Huang et al. 2014; Banik et al. 2016a). Recent findings indicated that developmentally regulated biological activity in maize is essential for favourable associations with the microbes in the rhizosphere. Under nitrogen deficiency, maize particularly gathers bacteria (Oxalobacteraceae) in the rhizosphere region, which promotes nitrogen uptake via lateral root growth regulation. The introduction of alleles encoding for advantageous flavones into maize varieties may boost the root system's connections with its growth-assisting rhizosphere microbes (Yu et al. 2021). As a result, using favourable plant-microbe associations as a selective target is a potential method for developing highyielding, nutritionally important crops. Daidzein was revealed to be a signalling molecule involved in the establishment of rhizobial symbiosis. In a recent study, it has been revealed that daidzein has other roles in altering the bacterial population in the rhizosphere region. Daidzein is secreted from soybean into the soils at the root surface, where it acts as a repellent rather than an attractant, assisting in the formation of a healthy microbial population (Okutani et al. 2019). 
The continuing COVID-19 outbreak (the severe acute respiratory disease SARS-CoV-2), is one of the most widely discussed scientific topics in the entire globe. Throughout a pandemic that is limiting people's lifespan all across the world, it is critical to examine all viable COVID-19 therapeutic alternatives. Flavonoids, which are one of the most significant plant compounds found naturally, may help with the therapy of COVID-19's severe inflammation (Liskova et al. 2021).

In this present review, we summarized in detail the recent progress achieved in unraveling the associative interactions between different microbial agents and plants through plant synthesized flavonoids and focused on how those flavonoids interact with microbes. We also considered the current trends, future research challenges, directions in development on flavonoids and their signalling pathways.

\section{Secondary metabolites}

Plants generate a wide variety of secondary metabolite compounds and most of these secondary metabolites perform a significant role in underground interactions, selection of soil microbes, or communications. The active secondary metabolites are biosynthetically obtained from primary metabolites. They are more restricted perhaps in their distribution throughout the plant kingdom as it differs in quantity and quality for a particular plant growing at various locations (Jain et al. 2019). The generation of secondary metabolites, although regulated by several genes, their particular expression is highly affected by different factors, including abiotic and biotic environmental conditions, such as edaphic factors and climate or other related living species (Mohiuddin 2018) (Fig. 1).

Specific roles of secondary metabolites:

- As a mediator of the symbiotic association between microorganisms and plant species, insects, nematodes, higher animals.

- Flavonoids have been shown to influence the availability of nutrients via soil physicochemical modifications (Cesco et al. 2010).

- In different reproduction-related functions.

- In cell communication processes within plants.

- As intermediaries of the plant's response to different abiotic and biotic stresses.
- As powerful weapons utilized against many bacteria, plants, amoebae, fungi, large animals, and insects.

- Some of the secondary metabolites elevate the rate of spore formation and stimulate or inhibit spore germination (Mohiuddin 2018).

Secondary metabolites perform a crucial role in the plants' adaptation to the changing environmental conditions and in resolving stress constraints. A wide variety of defensive functions are performed by such secondary metabolites in both abiotic and biotic stress conditions: photo-protective, signalling, antimicrobial, structure stabilizing (Ingle and Padole 2016). Plant secondary metabolites also play key roles in preventing pests and diseases, functioning as signals for plant-microbe symbiosis, and altering microbial populations connected with hosts (Fakhri et al. 2020). Many plants secondary metabolites' functions are yet unknown. While numerous PSMs and proteinmetabolite complexes have been discovered, the biological functions of the vast majority have yet to be established. Several outstanding reviews have been published that consolidate current findings reporting on the new activities of PSMs and emphasize the need for functional knowledge of the plant metabolome (Pang et al. 2021).

\section{Flavonoids}

Flavonoids are an important category of natural products, particularly belonging to PSM or plant secondary metabolites, with a polyphenolic backbone. They are ubiquitously found in plant photosynthesizing cells and are commonly present in seeds, roots, flowers, vegetables, honey, fruits, stems, nuts, wine, propolis, and tea (Panche et al. 2016). Having medicinal properties, they play a vital role in effective medical treatments (Bag et al. 2022b). Most of the flavonoids, if they are not substituted, are very poorly water-soluble (Kumar and Pandey 2013). Flavonoids are antioxidants and effective free radical scavengers that resist oxidative cellular damages and also have good anti-cancer activities. They are also used to promote aquaresis and as antimicrobial, anti-inflammatory, anti-allergic, and antispasmodic agents (Jain et al. 2019). Flavonoids can increase blood supply and may reduce blood pressure. It also has biochemical 


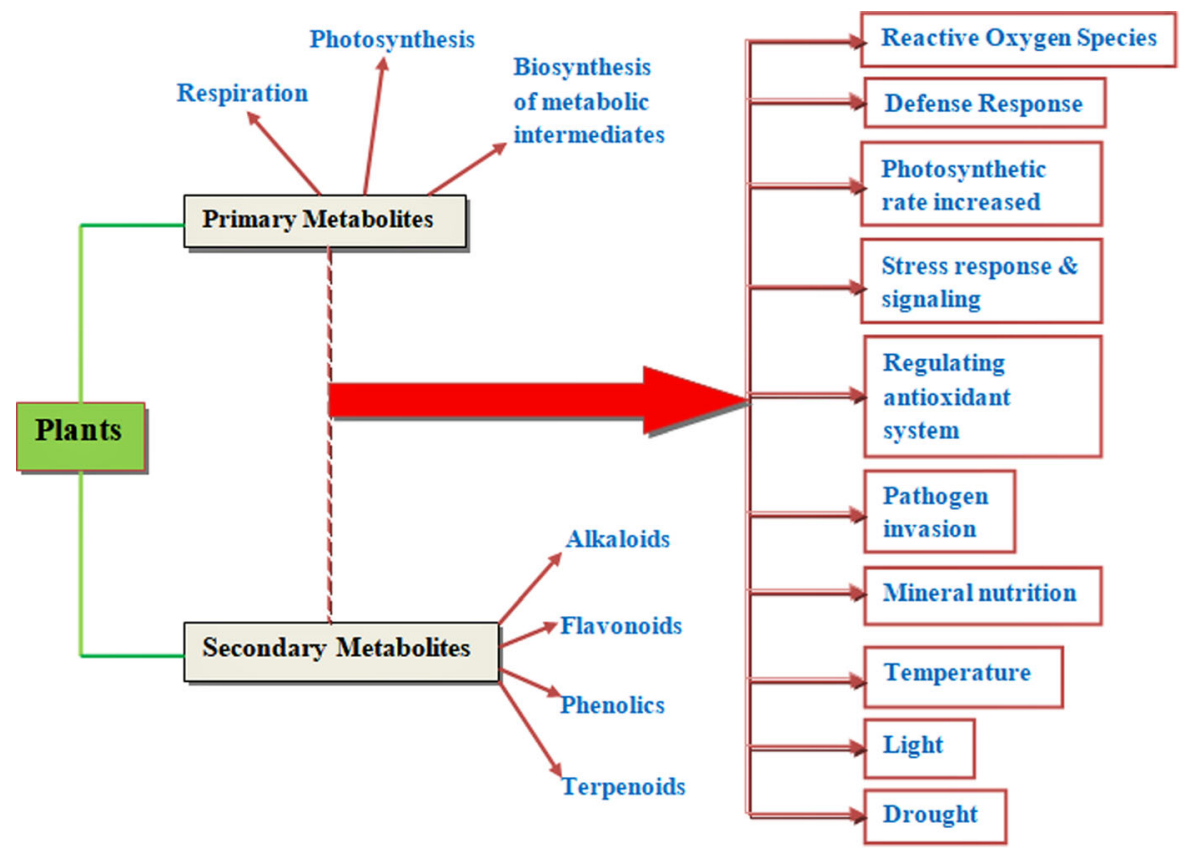

Fig. 1 Diversity and roles of plant metabolites. Plants undergo a range of stresses and biotic disruptions in their natural environments, resulting in the activation of stress and defensive responses induced by signalling mechanisms and different pathways to fulfil cellular functions necessary for physiological processes. The physiological mechanisms have an effect on

activities that prevent the action of certain enzymes such as lipoxygenase, aldose reductase, phosphodiesterase, xanthine oxidase, cyclooxygenase, ATPase, etc. The activities of various hormones (estrogens, thyroid hormones, androgens, etc.) are also regulated by flavonoids. Anti-inflammatory activity has also been shown by flavonoids in both exudative and proliferative stages of inflammation (Jain et al. 2019). Plant flavonoids are polyphenolic chemicals obtained mostly from vegetables, nuts, seeds, and fruits that are important components of green tea and cocoa-based beverages. Flavonoids have been proven to show anticancer effects through a variety of mechanisms, including anti-oxidation, inactivation of carcinogen, apoptosis induction, angiogenesis inhibition, and alterations of multidrug resistance (Goya-Jorge et al. 2021; Kapoor et al. 2021). Consumption of flavonoids has been demonstrated to have cardiovascular and antithrombotic therapeutic benefits due to antiplatelet action. Clinical and preclinical investigations have shown that flavonoid-rich phytoconstituents help to protect from heart diseases by inhibiting the primary metabolites, which provides different biosynthetic intermediates for secondary metabolites, with concomitant impact on biosynthesis of bioactive compounds. This is usually determined by the plant's genotype, species and cultivar, as well as its developmental stage and physiological condition

aggregation of platelets (Sharifi-Rad et al. 2021). Flavonoids have been reported to be produced in particular sites in plants and are also responsible for the aroma, colour of flowers, spore formation, seed germination, and growth of seedlings. Flavonoids also protect plant species from various abiotic and biotic stress effects and function as a special UV barrier, acting as signalling molecules, effective detoxifying agents, allelopathic compounds, and anti-microbial protective compounds (Jain et al. 2019).

\section{Biosynthesis of flavonoids}

Biosynthesis of different flavonoid compounds occurs through the condensation reaction between 4-coumaroyl-CoA and malonyl-CoA (3 molecules), performed by the enzymatic action of chalcone synthase (CHS). The two main precursors derive from two separate routes of cell metabolism: acetate and shikimate pathway that provide ring $\mathrm{A}$ and ring $\mathrm{B}$, with another chain linkages creating ring $\mathrm{C}$. Ring $\mathrm{A}$ is produced 
through acetate pathway from malonyl-CoA, chemically synthesized via carboxylation reaction of acetylCoA. Ring B and ring C (linking chain) is generated through the shikimate pathway from 4-coumaroylCoA. However, 4-coumaroyl-CoA is also directly produced from phenylalanine via the phenylpropanoid pathway (Nabavi et al. 2020). The aromatic ring structures formed through condensation reactions by all these pathways lead to the production of chalcone that will then generate a flavanone complex after isomerase-mediated cyclization. The later products undergo several additional modifications, like glycosylation, methylation, or hydroxylation, resulting in the diverse range of different flavonoid colours that we all see today (Shah and Smith 2020) (Fig. S1).

\section{Classification of flavonoids}

Most flavonoids are sub-categorized into different major groups, such as flavonols, anthocyanins, flavones, isoflavonoids, flavanonols, flavanones, flavanols, and chalcones (Panche et al. 2016). Furthermore, based on the attachment of ring $\mathrm{B}$ on different positions of ring $\mathrm{C}$, flavonoids have also been categorized into three main sub-groups, such as Isoflavonoids-3-benzopyrans,

Flavonoids-2-phenyl benzopyran, and Neoflavonoids-4-benzopyrans (Samanta et al. 2011). Different major flavonoid groups and their associated compounds are summarized below:

- Flavonols: Kaempferol, myricetin, quercetin.

- Flavones: Chrysin, apigenin, luteolin.

- Flavanones: Hesperitin, naringin, naringenin.

- Isoflavonoids: Daidzein, glycitein, genistein.

- Flavanols: Catechin, epigallocatechin, epicatechin.

- Anthocyanidins: Pelargonidin, cyanidin, delphinidin.

- Chalcones:

Naringeninchalcone, eriodictyolchalcone.

\section{Transport}

Flavonoids, particularly anthocyanins are abundant in plant leaves, seed coverings, fruits. The anthocyanin biosynthetic route has received a lot of research, but the underlying mechanisms of anthocyanin transportation from the biosynthesis site to the storage location are still being investigated. We have highlighted the developing functions of transporters engaged in the transfer of anthocyanins to the vacuole in the following sections. Microscopy findings originated the idea of a vesicle-mediated flavonoid transport system. Anthocyanoplasts were originally thought to be anthocyanin biosynthesis sites or transport vesicles (Braidot et al. 2008; Zhao and Dixon 2010). These cytoplasmic anthocyanin entities are formed from a relatively large number of smaller-sized vesicle-like structures that eventually fuse together and are protected by a membrane. AVIs (AnthocyanicVacuolar Inclusions) are similar cellular complexes that are found in the vacuoles of many animals and exhibit dynamic moments. Although their association with membranous substances and particular proteins, AVIs aren't surrounded by a membranous structure (Zhang et al. 2006) and are much more likely to be storage components than to be associated with the transport of anthocyanin. After AVIs have been integrated into the vacuole, cytoplasmic vesicular structures containing anthocyanins have been found to interact with them. By fusing PVCs (prevacuolar compartments) and then the central vacuole, these cytoplasmic vesicular structures could be transported into the central vacuole (Fig. 2). Furthermore, anthocyanin-containing vesicular complexes can co-localize with PSVs (protein storage vacuoles) and transport anthocyanins in a TGN (Trans Golgi Network)-independent endoplasmic reticulum to PVC (prevacuolar compartments) vesicle trafficking route. (Poustka et al. 2007; Zhao and Dixon 2010). This transporter-mediated pathway is promoted by ABC (ATP-binding cassette), MATE (Multidrug and toxin extrusion compound), and BTL (Bilitranslocase)-like transporters (Fig. 2). In this transport system, anthocyanins are transported to vacuoles through autophagy, either micro- or macro-autophagy (Kaur et al. 2021; Michaeli et al. 2014). GSTs function as ligandins, via the formation of glutathione conjugated anthocyanins, to accommodate the efficient and dynamic transport of anthocyanins. A complicated process transports anthocyanin end-products from the site of production to the vacuole in plant tissues. Vesicle transportation and vacuolar membrane transporters give various pathways for vacuolar sequestration of anthocyanin (Kaur et al. 2021). Overall, the evidence presented here provides a current peek into 


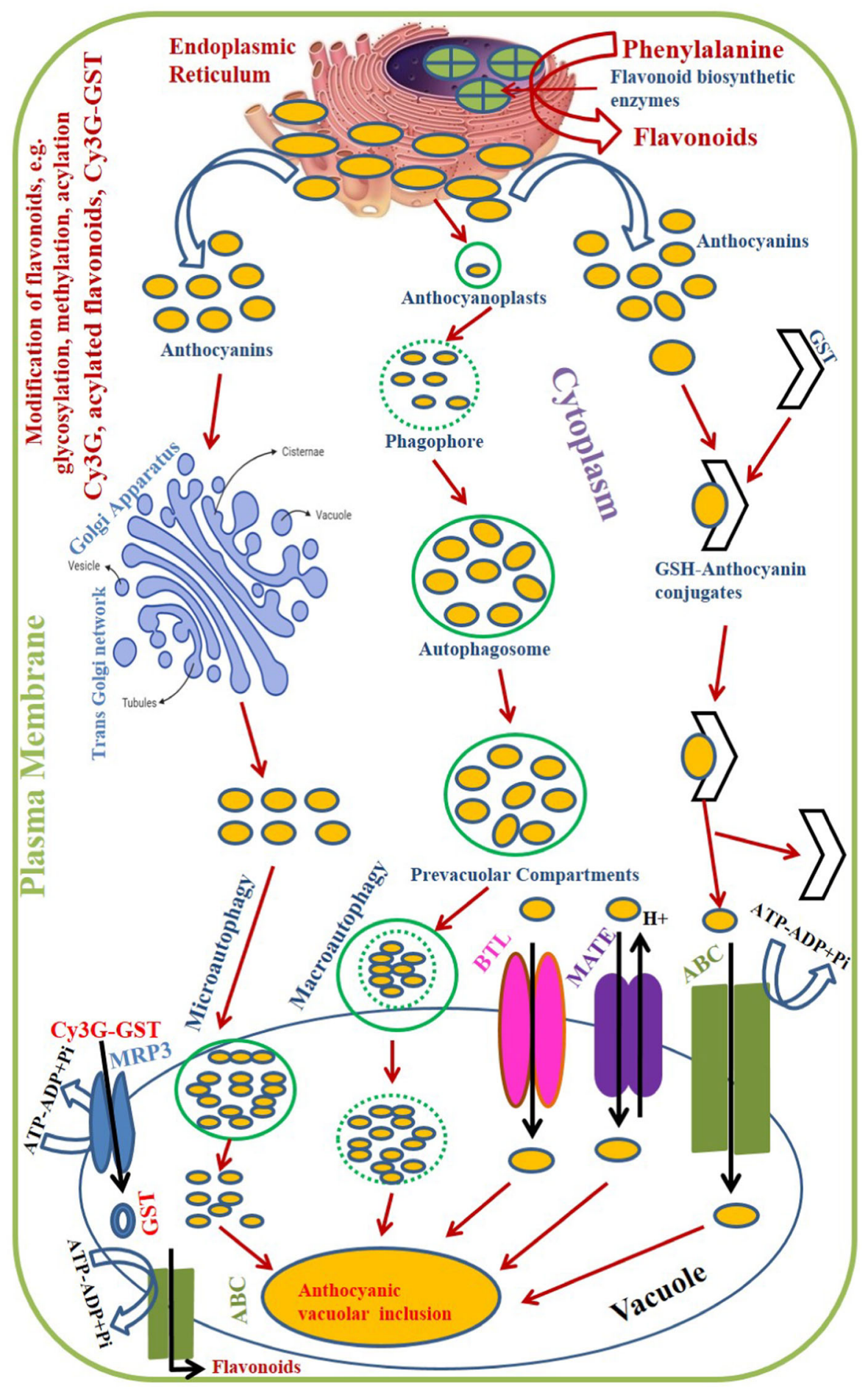

how altering the function of transporters might aid in the anthocyanin enrichment of tissues.
Auxin transport is modulated by flavonoids, which influence the production and distribution of PIN proteins, and also the recycling of PIN proteins into 
4Fig. 2 Vesicle mediated flavonoid transport. After anthocyanin biosynthesis (biosynthetic site-endoplasmic reticulum), they are transported to the vacuolar membrane and sequestered. Anthocyanins are transported by macrophagocytosis or microphagocytosis via ER-derived vesicles. On the other site, the transporter-mediated pathway is facilitated by vacuole-associated proteins such as ABC, BTL and MATE-like transporters. GSTs function as ligandins, via the formation of glutathione conjugated anthocyanins, to accommodate the efficient and dynamic transport of anthocyanins from endoplasmic reticulum to vacuoles

endosomal vesicles and the function of ABCB-type auxin transporters. Auxin exportation can be inhibited by external administration of some flavonoids, particularly flavonols, and auxin transportation in transgenic plants or flavonoid-deficient mutants is changed. Furthermore, flavonoids are essential to regulate auxin transportation during nodule commencement in legumes that produce indeterminate nodules, and flavonols seem to be the most likely flavonoid subtype to be involved in this auxin transport regulation $(\mathrm{Ng}$ et al. 2015; Morales-Quintana and Ramos 2021).

In stress response or localized rhizosphere circumstances, roots tissues may quickly synthesize and discharge vast quantities of phytochemicals, hence the creation and transit of these molecules in cells are frequently related. Plants must deposit potentially dangerous phytochemicals and intermediates towards the vacuole or other membrane-bound compartments to control them. Such divisions offer safe storage locations as well as methods for transporting bioactive compounds securely throughout the cytoplasm. Exocytosis or membrane-associated transport proteins are used to discharge molecules into the apoplast (Weston et al. 2012). The Arabidopsis thaliana transparent testa12 (tt12) mutant, which encodes a membranous protein of the multidrug and toxic efflux transporter family, was phenotypically investigated, and it was discovered that TT12 is implicated in the vacuolar aggregation of proanthocyanidin progenitors in the seed. In tt12 seeds, metabolites analysis revealed a lack of proanthocyanidins and flavan-3-ols, as well as a decline in the key flavonol quercetin-3-O-rhamnoside (Marinova et al. 2007).

The discovery and operational characterization of a membrane-localized LaMATE2 (MATE-type transporter) implicated in the transfer of genistein from roots of white lupin are described in a recent paper.
During nitrogen insufficiency and also low phosphate bioavailability, 2 nutritional deficits that cause the production of this isoflavonoid, LaMATE2 production in the root is increased. Silencing LaMATE2 decreased genistein outflow and much more so the development of symbiotic nodules, indicating that LaMATE2 is important for isoflavonoid nodulation and production (Biała-Leonhard et al. 2021).

\section{Flavonoids in signalling events}

Flavonoids are uniformly distributed throughout the plant kingdom and are known for their various and determinant functions in plant growth and development, plant physiology, and also in the success and effectiveness of plant-rhizobia associations. Flavonoids also perform an important function in plantmicrobe interactions, primarily arbuscular mycorrhizal (AM) symbioses and plant-rhizobia (Singla and Garg 2017). In symbiotic legume-rhizobia interactions, certain flavonoids also act like signalling molecules inducing nodule formation by stimulating nodulation $(n o d)$ gene transcription in rhizobia (Liu and Murray 2016).

\section{Flavonoids as signal molecules in leguminous plants}

Legumes, which are capable of setting up a symbiotic relationship with $\mathrm{N}_{2}$-fixing bacteria, designated as rhizobia, permit them to develop in nitrogen-deficient soil. The symbiotic relationship between rhizobia and legumes is based on a molecular communication between both associates, in which flavonoid compounds have been involved with their distinctive roles. Other well-recognized functions of flavonoids in the soil rhizosphere portion of the root of plants include rhizobia chemo-attraction, and increase of the transcriptional activation of nod related genes from symbiotic organisms. Diverse rhizobia express a differential response to a specific flavonoid. A recent study reported that $S$. meliloti was not attracted to any of the flavonoids found in seed exudates of alfalfa (Compton et al. 2020). Luteolin released from alfalfa roots acts as an inducer for Rhizobium meliloti, and hesperetin released from pea roots acts as an inducer for Rhizobium leguminosarum bv. viciae. 
Interestingly, some of the flavonoids released by certain legume plants may act as an anti-inducer for other rhizobia (Novák et al. 2002). Under normal circumstances, plants produce a broad variety of flavonoid compounds in the root and shoot that play an important function in the formation and development of the meristem nodules in plants (Sundaravarathan and Kannaiyan 2002; Khalid et al. 2019). The formation of nodules in leguminous plants begins with signal communication among plant-specific signalling molecules (flavonoids) released by symbiotic partners and plant root cells (Subramanian et al. 2007). Some of these chemicals (flavonoids) are mild or powerful inducers, while others are antagonists or have no impact on nodulation. Certain flavonoids produced by legume plants may serve as an antiinducer or as a competitor for other rhizobia. It is widely known that combinations of extracellular chemicals generated from legumes are considered to serve as signals that influence the competitiveness of rhizobia towards legumes (Liu et al. 2017). Which chemicals, or classes of chemicals, trigger the most nodulation differs between symbiotic pairings. Rhizobium leguminosarum bv. viciae is stimulated by hesperetin secreted from pea roots (Novák et al. 2002). Genistein, naringenin, genistein, daidzein, and coumestrol are the most effective inducer for Phaseolus vulgaris. Other groups of chemicals released by this plant are flavonols, flavones, isoflavonoids, and anthocyanidins. The most efficient plant-to-bacteria signalling for soybeans (Glycine $\max$ ) has been identified as an isoflavone, jasmonic acid, and its derivatives, or genistein. Flavonoids are the primary chemicals produced by leguminous roots, which vary with species (Lira Jr et al. 2015). When bacteria get these chemical impulses, they produce Nod factors. These factors cause physiochemical changes in the host species, culminating in root infections and organogenesis of nodules. The bacterial species and host plant communicate by chemical signalling exchange, wherein the bacteria detect organic substances exuded by roots, like flavonoids, which stimulate the production of rhizobia genes necessary for nodulation (Bosse et al. 2021). The transporters involved in flavonoid production during arbuscular mycorrhizal symbiosis have yet to be discovered. Nitrogen shortage stimulates flavonoid production and release, similar to the increased exudation of strigolactones before arbuscular mycorrhizal symbiosis under phosphate-limiting circumstances. Thus, the identification of "pre-infection flavonoids" transporters may be determined based on their root-specific transcription and elevation under nitrogen deficiency (Banasiak et al. 2021). Because various legumes employ different flavonoids components for nodulation, the prospect of differences in transporters selectivity or expression among legumes is intriguing. Furthermore, it has been reported that the transfer of phenylpropanoid metabolites affects plant-microbial associations. It is believed that different flavonoid transporters must be located in the plasma membrane of plant root cells to release these chemicals into the rhizosphere region and trigger the transcriptional activation of rhizobial nodulation genes, therefore starting legume-rhizobium symbiosis. However, it is unknown if various flavonoids have a role at different phases of modulation. Interestingly, despite the significance of this first step, the identification of the flavonoid transporters remains undisclosed. Furthermore, biochemical investigations have shown that ABCG transporters regulate genistein production from Glycine max roots, although the particular components have yet to be identified. Representatives of the MATE family have been reported to be engaged in the secretion of signalling flavonoids; nevertheless, this has yet to be confirmed (Banasiak et al. 2021).

In such leguminous plants, flavones trigger the activation of nodulation genes by binding NodD transcriptional activator of the corresponding symbionts (Cooper 2004; Xia et al. 2017). NodD is a transcriptional stimulator that belongs to the LysR family. Representatives of the LysR group are $35 \mathrm{kDa}$ with N-terminal helix-turn-helix DNA binding domain, commonly exhibit auto-repression, and typically need inducers to operate. It has been demonstrated that flavonoids attach to the carboxy terminus domain of the NodD protein by creating chimerical NodD proteins (Peck et al. 2006; Walker et al. 2020). The exudation of flavonoids also varies at various stages of the development of the symbiotic relationship (Singla and Garg 2017). The structure, shape, and composition of flavonoids may also be changed by the metabolic processes of symbionts (Weston and Mathesius 2014). The precise methods of nod gene stimulation are also unknown: NodD may bind to the nod box as a dimer or oligomer and NodD binding to DNA may be enhanced by flavonoids. It is unknown how NodD reacts with RNA polymerase to trigger the 
expression of nod genes. This initial stage in the molecular dialogue between the legumes and rhizobia leads to host selectivity: a rhizobial species' NodD protein stimulates expression of nod gene in the presence of flavonoids generated by suitable hosts. Distinct NodD proteins can have various inducer particularities, and a nodD mutant in one rhizobial species may not be supplemented by a nodD gene from other rhizobia (Mbengue et al. 2020). Plant-generated flavonoids activate NodD protein, which binds to nodbox in the promoter region sequences of respective nod genes, promoting the production of nodulation (Nod) factors. These complexes interact with the receptors of the Nod factor situated on the cell membrane of plants and initiate a signal transduction cascade. This signal stimulates numerous gene expressions, formation of infection thread, leading to deformation of root hair, followed by the formation of infection thread, biosynthesis of flavonoids, cortical cell division, and ultimately, formation of root nodules
(Mierziak et al. 2014). Symbiotically essential nod gene expressions are promoted by naringenin, a flavonoid compound during symbiotic association between Phaseolus vulgaris (bean plant) and Rhizobium etli CE3 (Meneses et al. 2017). In addition, several molecular and physiological studies should be performed to investigate the involvement of flavonoids in the defence mechanisms of plants against different pathogenic microbial agents and also in the selection and recruitment of advantageous symbionts (Fig. 3).

During early signalling events, leguminous plants and rhizobia can select each other's partners based on their compatibility. The secretion of flavonoids from the roots of the potential plant host is the initial stage in this exchange. Legumes have a wide range of flavonoids, although research shows that only a fraction of them are engaged in symbiosis. Certain flavonoids show enhanced production in response to rhizobial inoculation, but they do not trigger

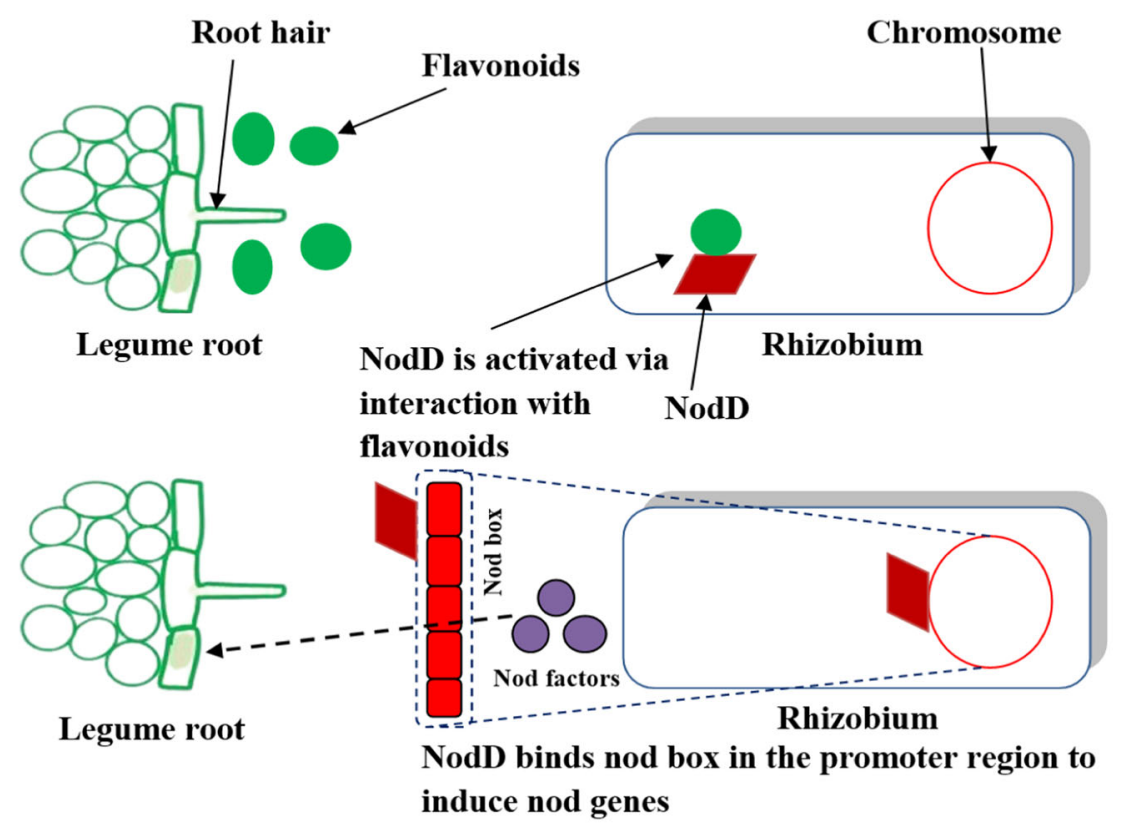

\begin{abstract}
Rhizobia invade legume root to form $\mathrm{N}_{2}$ fixing nodule
\end{abstract}

Fig. 3 Signalling interactions between Rhizobium and legume root. Flavonoids are secreted by legume roots to Rhizobium. That plant secreted flavonoids enter the cytoplasm of Rhizobium through cell membrane and activate rhizobial NodD by conformational modifications. Activated NodD binds to the
Nodule formation is induced by nod factors \& the nod

factor also determines its activity on various hosts nod box in the promoter region of nod genes to induce the enzymatic expressions needed for nod factors synthesis. Nod factors attach to it's receptors on plant root hairs to induce nodule formation by deformation of root hair and cortex cell division 
expression of nod gene, instead of functioning as antimicrobial compounds. The fact that these flavonoids are released particularly in response to rhizobia suggests that they have been still engaged in the rhizobia-legume symbiotic relationship (Walker et al. 2020). More comprehensive information on the dynamics of flavonoids production and how it affects nodulation, the productivity of legume plants will be needed.

\section{In silico binding studies of NodD protein of Rhizobium leguminosarum bv. trifolii (UniProtKB-P04680) and flavonoids}

Information related to different flavonoid components, their sources, microbes, major functional roles in plants, genes, and proteins were retrieved using search engines viz. PubMed, PubChem, Scopus, ScienceDirect, Google Scholar, Springer Link, National Center for Biotechnology Information (NCBI), Protein Data Bank (PDB), UniProt, etc., and summarized in Table 1 . The results were cross-referenced to generate a total of 163 references cited in the present work including data from 1987 to 2021 . A total of nineteen flavonoids were selected based on their selective beneficial interaction with plant-related beneficial microbiome. As fourteen of these flavonoids interact with different species of Rhizobium (except sl. no. 10, 12, 14, 16, and 19 of Table 1), we have selected NodD protein of Rhizobium leguminosarum bv. trifolii (UniProtKB-P04680) as the most appropriate template (SMTL ID: 5ae5.1) to perform the in silico studies. The NodD protein of Rhizobium leguminosarum bv. trifolii was selected as it shares higher sequence identity with other members of Rhizobiacea family [Sinorhizobium fredii (UniProtKB-P55359) $=69.7 \%$, Bradyrhizobium japonicum (UniProtKB- P12232) = 68.1\%, Mesorhizobium japonicum (UniProtKB$\mathrm{Q} 52838)=67.4 \%]$. The SDF files of the 3D structures for the selected flavonoids were downloaded from PubChem (https://pubchem.ncbi.nlm.nih.gov/) and then converted into PDB files through PyMOL software. The 3D structure of the NodD protein of Rhizobium leguminosarum bv. trifolii (UniProtKBP04680) was generated using SWISS MODELLER (https://swissmodel.expasy.org/) and the FASTA format of the said protein sequence. Thereafter, the PDB file was obtained for the same. The molecular docking was performed through AutoDock 4.2 tool to get the complexes of NodD protein and each flavonoid to determine the binding affinity (in $\mathrm{kcal} / \mathrm{mol}$ ) between them. More negative binding affinity indicates stronger interaction (Morriset al. 1998). Moreover, LigPlot was used to know the interacting residues between them within the complex (Laskowski and Swindells 2011).

From the molecular docking analysis, it's clear that all the flavonoids are not binding in the same region of the homotetramer complex of NodD protein (Fig. S2). But, among these selected flavonoids there are some similarities in the binding sites and there are 5 binding sites for the selected 19 flavonoids. According to the binding regions the selected flavonoids can be grouped as follows: (i) Galangin, (ii) Catechin and Genistein, (iii) Galangin-3-methyl ether, Quercetin-3-O-arabinoside and Dihydrokaempferol, (iv) Rutin, Kaempferol, 7,4'-dihydroxyflavone and Kaempferol-3rutinoside and (v) Isoliquiritigenin, Quercetin, Naringenin, Apigenin, Apigeninidin, 3,6-Dihydroxyflavone, Liquiritigenin, Luteolin and Anthocyanins. Furthermore, the average binding affinity of the selected flavonoids is $\sim-8.15 \pm 0.42$. The binding affinities of the flavonoids in a particular region showed similarity with few exceptions e.g., in the region (ii) the binding affinities of the flavonoids are -7.7 and -7.6 and comprised of a similar number of hydrogen bond formation and hydrophobic interactions with the NodD protein complex. In region (v) the binding affinity is $\sim-8.3$ but exceptionally low for Liquiritigenin and high for 3,6-Dihydroxyflavone. For Liquiritigenin there is no hydrogen bond in between this flavonoid and the NodD protein complex but for 3,6-Dihydroxyflavone there is one hydrogen bond along with hydrophobic interactions as for Liquiritigenin. The binding affinities of the flavonoids will vary based on the number of hydrogen bond formations and the number of hydrophobic interactions with variable strength (Fig. 4; Fig. S3).

\section{Flavonoids in Mycorrhizal symbiosis}

Chemo-stimulation, root exudation, and the involvement of other microbial populations in the soil rhizosphere region may influence mycorrhizal symbioses and colonization patterns. The function of flavonoids in the development of an association 
between AM fungi and plants are also well recognized and is particularly important for most plants in nutrient-deficient soils especially, phosphorus (Nagata et al. 2016). The influence of formononetin, on the yield and production of potato facilitated by Arbuscular Mycorrhizal Fungi (AMF), were analyzed. The findings showed an improvement in plant dry weight, the development of tubers, and the efficiency of phosphorus utilization. Possibly, the results were more pronounced at low phosphorus concentrations. Melon roots were investigated for secondary metabolite variations during AM fungal (Glomus caledonium) invasion in a study. The concentration of a C-glycosylflavones was found to be significantly higher in non-inoculated control roots cultivated under phosphate-limited situations, and the flavonoid substantially enhanced mycorhizal colonization in melon roots cultivated under higher and lower phosphate situations (Akiyama et al. 2002). Additionally, formononetin improved sporulation in mycorrhizal fungi extra than threefold (Davies et al. 2005). There was a correlation found between the percentage of root colonization and the number of entrance points for the particular examined AMF (Glomus mosseae, Gigaspora margarita, Glomus intraradices, and Gigaspora rosea). Flavonols (morin) and flavones (luteolin and chrysin) increased the number of entrance points and root colonization, while rutin and kaempferol have no overall impact on root colonization patterns and presymbiotic AMF growth (Scervino et al. 2007). The flavonoids, such as hesperetin, naringenin, apigenin increased hyphal growth, root colonization patterns, and rate of spore germination in Gigaspora margarita (Nakabayashi et al. 2014). Root secreted flavonoids have also been shown to boost mycorrhizal symbioses by promoting spore germination of fungus, root colonization, and hyphal growth (Shah and Smith 2020). Perhaps, the higher root hyphal growth enhances the root surface area to facilitate AMF colonization. In a study, it has been found that greater flavonoids levels in $T$. sebifera roots from introduced communities are associated with higher AMF colonization rates that contributing to their fast development (Pei et al. 2020). In a recent study, it has been demonstrated that plants from imported communities had higher flavonoids (quercetin) levels in root exudates, more AM fungal colonization, and higher productivity. When exudates sources were from imported communities, applying root exudates more strongly promoted germination of AM fungal spore and AM fungal colonization of targeted plant species (Tian et al. 2021). A study has been conducted to investigate the impact of AM symbiosis on flavonoids accumulation in $S$. rebaudiana, and also trichome quantity and growth Colonized plants had a substantial rise in root and leaf dry mass, along with total leaf surfaces, as compared to non-colonized plant species (Sarmiento-López et al. 2021). Quercetin, a flavonoid compound was found to be an effective agent in promoting mycorrhizal flourishing regardless of genotype (Gomes et al. 2021).

Flavonoids have been reported to solubilize $\mathrm{P}$ (phosphorus) by improving mycorrhizal root colonization and may assist in the supply of nutrients and mineralization of nitrogen and other additional nutrients (Dakora and Phllips 2002). They can also serve as metal chelating operatives, essentially making some micronutrients much more available to the plants (Gupta and Chakrabarty 2013). Flavonoids discharged from white lupine roots caused substantial rises in phosphorus acquisition (Tomasi et al. 2008). Isoflavonoid found in alfalfa root exudates has been shown to dissolve iron phosphates, allowing both phosphorus and iron far more available to the plants. Flavonoids, such as kaempferol, genistein, and quercetin, can make Fe more available by chelating and converting oxides of iron from ferric $\left(\mathrm{Fe}^{3+}\right)$ to ferrous $\left(\mathrm{Fe}^{2+}\right)$ ions in the rhizosphere (Cesco et al. 2010) (Table 1).

\section{Flavonoids in non-rhizobial plant-bacterial interactions}

Some of the extensively researched mechanisms in plant-microbial interactions include microbe or plant signalling, quorum sensing, pest control, and volatile compound production (Banik et al. 2019; Sharma et al. 2020; Basit et al. 2021). The flavonoid naringenin works as a signalling molecule, causing A. caulinodans to invade the rice roots in substantial amounts. Naringenin levels have been observed to boost $A$. caulinodans colonization in rice roots' xylem and cortical area (Shamala et al. 2018). Root-exuded flavonoids have a function in the Oxalobacteraceae recruitment in maize, which increases lateral root development and hence facilitates nitrogen absorption, according to a new study. Furthermore, the 


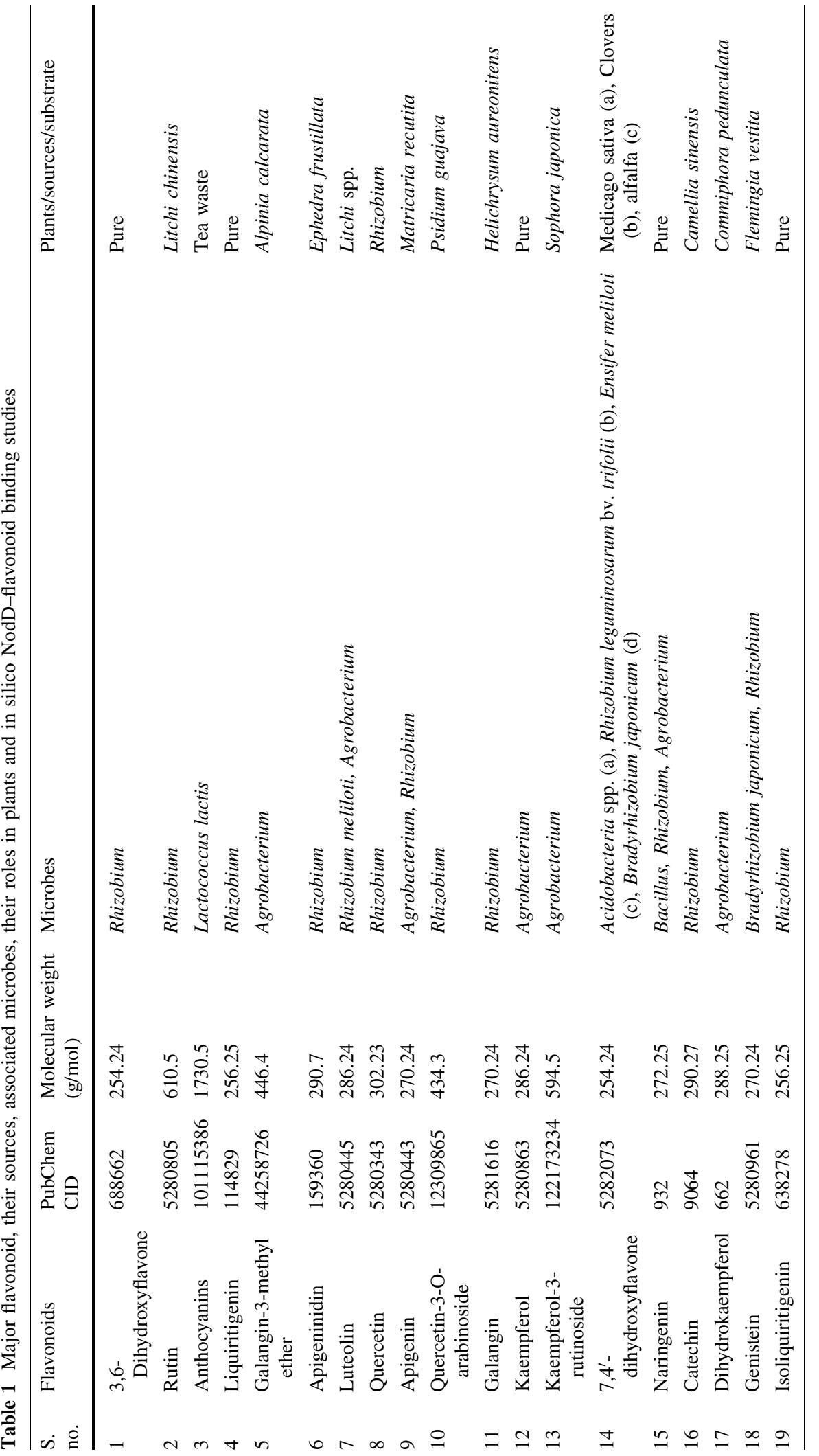




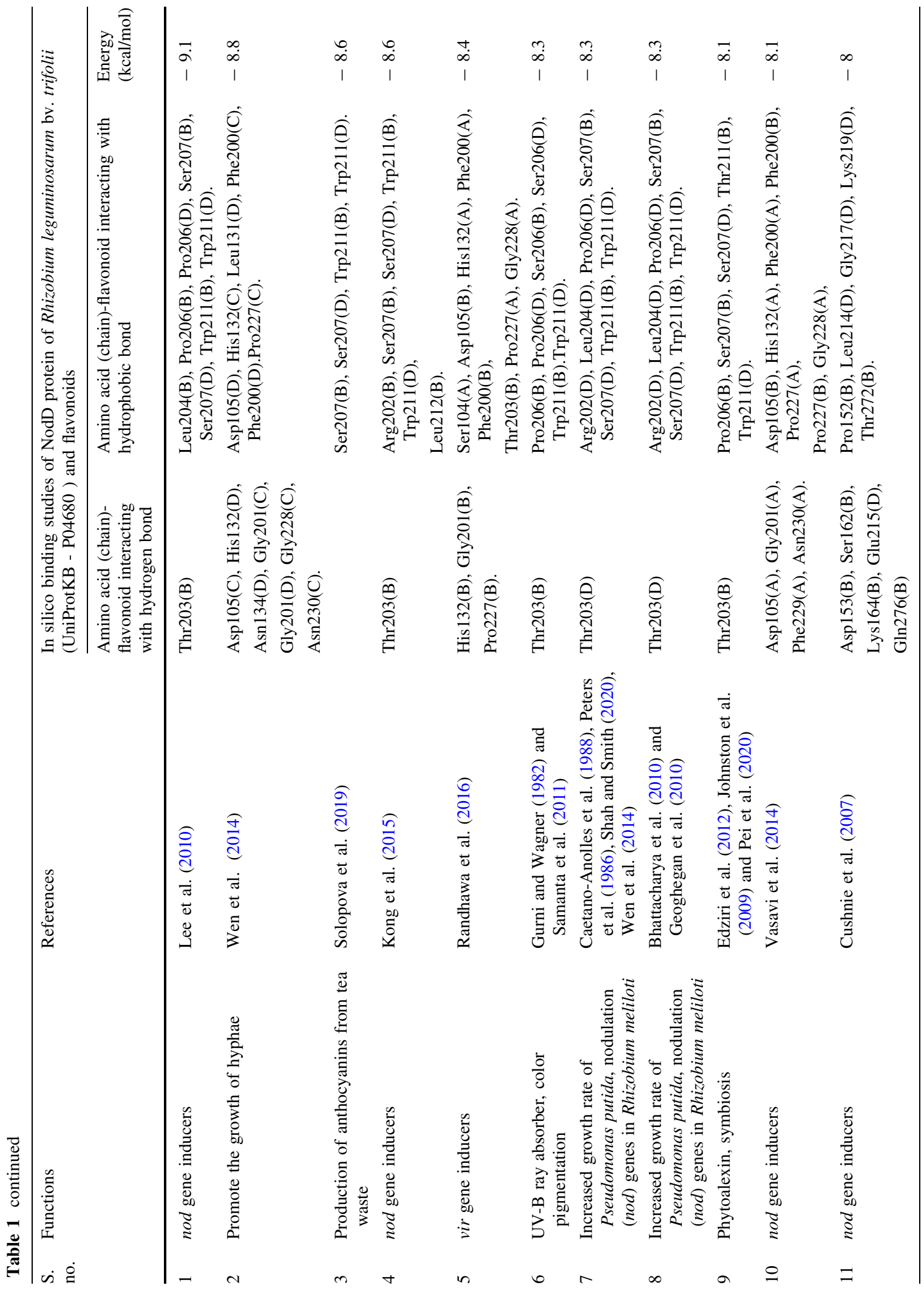




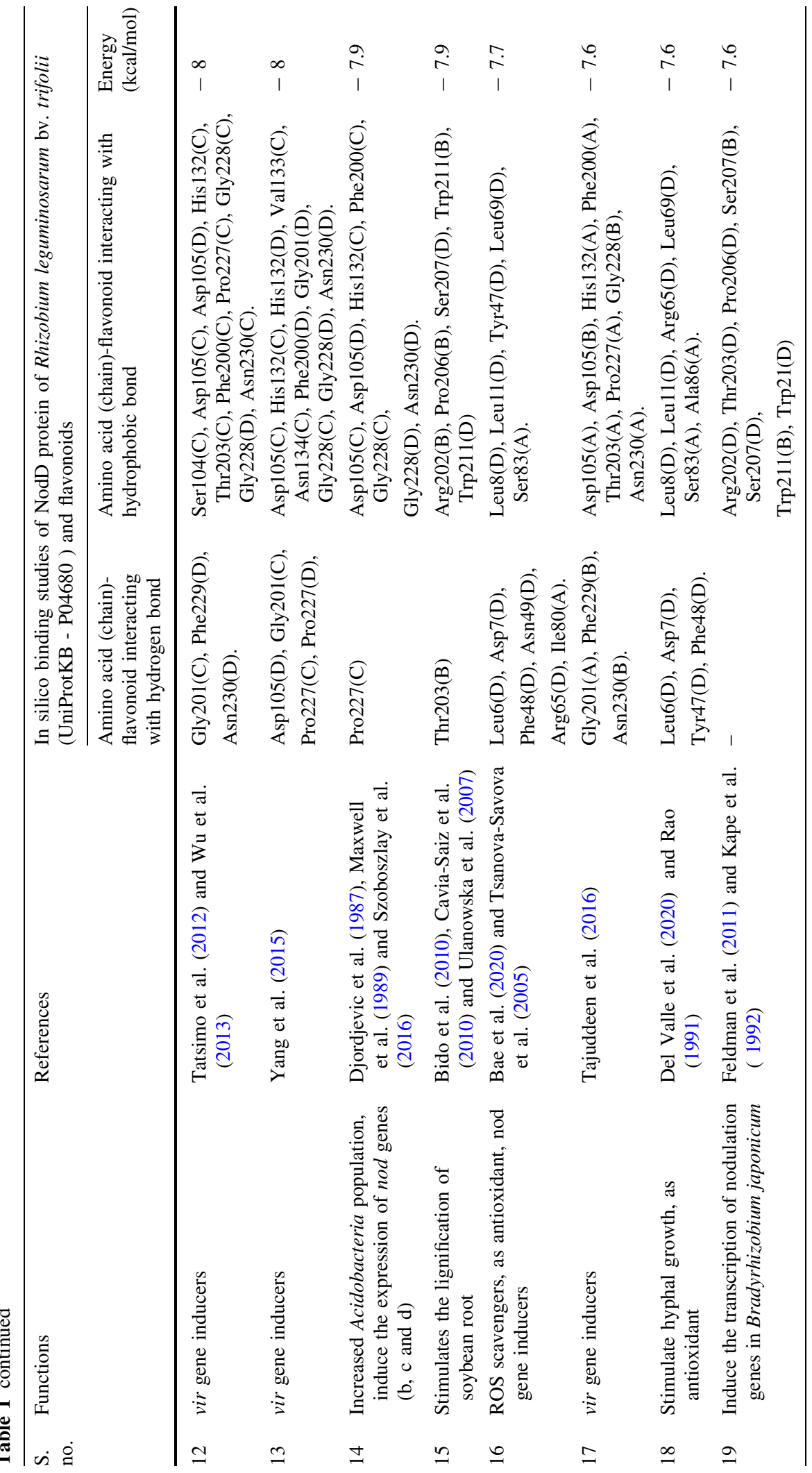




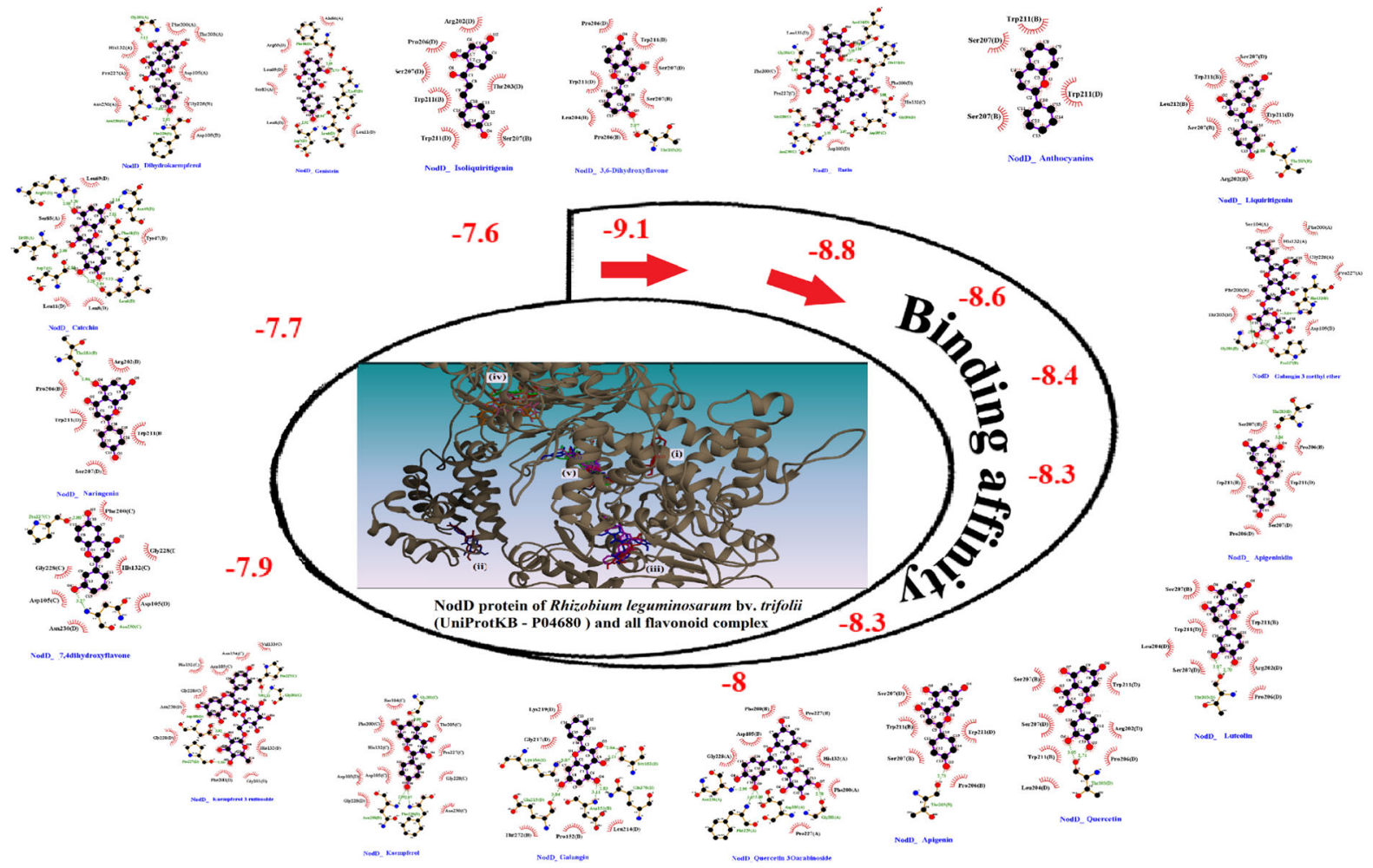

Fig. 4 In silico binding studies of NodD protein of Rhizobium leguminosarum bv. trifolii (UniProtKB - P04680) and each flavonoids (Table 1). Here NodD-flavonoid complex were arranged based on their binding affinities (more negative values represent stronger interaction). EachNodD-flavonoid complexformhydrogen (green dotted line between amino acid and

existence of coumarins in root exudates has been shown to alter the microbial diversity of the root by enhancing or preventing the development of particular microorganisms (Abedini et al. 2021).

Flavonoids have been discovered to prevent a variety of root diseases and pests, including bacteria, fungus. This is due to their antibacterial toxins and pro- or anti-oxidant properties. Although substantial proof is lacking, their function as antioxidants inside the plant is thought to be beneficial (Hassan and Mathesius 2012). Flavonoids' transportation and preservation are closely controlled due to their strongly oxidative nature, which accounts for some of the significant information deficiencies. As a result, the strategy by which these chemicals become accessible to counteract oxidative damage in the case of a pathogen assault remains a mystery.

When a pathogen is present, de novo production of flavonoids phytoalexins with antibacterial and flavonoid) andhydrophobic bond (red half circles) during NodD-flavonoid interaction. The central picture (present inside the oval circle) predicted binding sites of 19 flavonoids in NodD protein of Rhizobium leguminosarum bv. trifolii (UniProtKBP04680 ). Individual higher regulation figures have been supplied in supplementary data (Figs. S2, S3)

antifungal properties can occur. These compounds may also be stored inactively to serve as phytoanticipins, which can be used to generate a rapid response against future infections. Whenever $M$. truncatula were attacked by Phymatotrichopsis omnivora, the source of cotton root rot disease, global gene expression investigations revealed an increase in flavonoid production. Pathogens including $R$. solani, N. haematococca, and Phymatotrichopsis omnivora have 'adapted' to avoid several of these flavonoids to colonize the plant effectively (Hassan and Mathesius 2012). Flavonoids, however, may attract pathogenic microbes like $P$. syringae and $A$. tumefaciens as well as trigger their virulence traits. Flavonoids were shown to stimulate oviposition in the monarch butterfly. Flavonoids are considered to have substantial phagostimulatory properties, though their impact on food choices hasn't always been confirmed (Treutter 2006). A recent study into natural treatments for biotic 
stress has resulted in the development of novel items that combat disease-causing organisms. A novel molecule, recognized as an isoflavonoid, was obtained from the Erythrina poeppigiana roots and contrasted with 5 other root strains against Staphylococcus aureus. Inoculated pathogenic agents showed substantial inhibitory activity, according to the findings. The production of isoflavonoid in the leaves of soybean in reaction to infection by $P$. glycinea was studied. The primary phytoalexins generated in reaction to non-pathogenic (P. lachrymans) and pathogenic $(P$. glycinea) inoculums of leaves soybean were recognized as daidzein and coumestrol. The findings showed that coumestrol inhibited harmful bacterial colonization and indicated that susceptibility to $P$. glycinea in leaves of soybean was related to enhanced buildup of isoflavonoids (Shah and Smith 2020). By inoculating Pseudomonas spp. with bean plants, the synthesis of phytoalexins in the leaves of beans was investigated. Affected bean leaves contained coumestrol, a phytoalexin isoflavonoid that reduced the development of 2 pathogenic bacterial strains: $P$. phaseolicola and P. marsprunorum. After infection, coumestrol was obtained from susceptible and hypersensitive regions. Their aggregation explains why bacterial colonization is inhibited in resistant and hypersensitive bean leaf lesions (Shah and Smith 2020). Cinnamic acid (CA) administration has been shown to inhibit the proliferation of F. culmorum Pz11 and maize. Furthermore, CA treatment can suppress the synthesis of flavonoids by fungi and plants, but it does not affect the production of sugars as well as IAA. F. culmorum Pz11 has the potential to colonize maize roots and encourage their development. PZ11, on the other hand, was unable to colonize maize roots efficiently and reduce CA-induced stresses (Mehmood et al. 2019).

Engineering plants with enhanced or inducible production of effective flavonoids would be an appealing chance to improve plant protection; nevertheless, to prevent pathogen susceptibility, the plant may need to synthesis a variety of potent antimicrobial flavonoids. Furthermore, it would be critical to determine if ectopic production of these flavonoids will affect favorable rhizosphere microorganisms. Traditional approaches are insufficient for gaining a full understanding of the metabolic changes, but emerging "omics" technologies unquestionably provide a framework for doing so. Furthermore, metabolomics aids in the detection and characterization of flavonoids, and it has often been utilized as a major approach for identifying the flavonoid components implicated in plant-pathogen biological control.

Main targets for enhancing beneficial plant-microbial interactions include quorum sensing, motility of bacterial species, biofilm formation, and different signalling pathways associated with plant-microbial interactions (Farrar et al. 2014; Banik et al. 2016b). Microbial cells in biofilm interact via numerous signalling substances to modify their operational mechanisms via coordinated release of antibiotics and toxins, as well as in gene expression modulation via quorum sensing (Rayanoothala et al. 2021). The network and mechanism of quorum sensing-mediated communication system on plant-microbe interaction are shown below (Fig. 5). In leguminous plant-Rhizobium symbiotic association, plant secreted flavonoids induced AHLs synthesized genes expression in rhizobia (Pérez-Montaño et al. 2011). Whereas Gypsophila, cytokinin, IAA affects quorum sensing and activity of gall formation by Pantoeaplantarum (Chalupowicz et al. 2009). Thus, it is suggested that quorum sensing is a plant-microbial interaction network that should be considered as bidirectional, i.e. regulated by both plants and microbial collaborators. If flavonoids are quorum-sensing imitators and stimulators at substantial quantities in plant-associated bacteria, this might be investigated as a way to change bacteria's capacity to colonize and invade host plants.

Flavonoids will soon be generated using biotechnological technologies such as heterologous network incorporation into selected hosts and genetic modifications, rather than just plant extracts. This genome engineering strategies, when combined with growth optimization procedures, will be an appropriate solution to address the growing market requirement for flavonoids in the biopharmaceutical business. The expansion of flavonoid synthesis might have a significant impact on the worldwide business sectors.

\section{Conclusion and future perspectives}

This review explored the strength and scope of plantmicrobial interactions through secondary metabolites, highlighting current progress in this area. The chemical nature, classifications, functional roles of flavonoids, and their signalling behaviour in different plants 


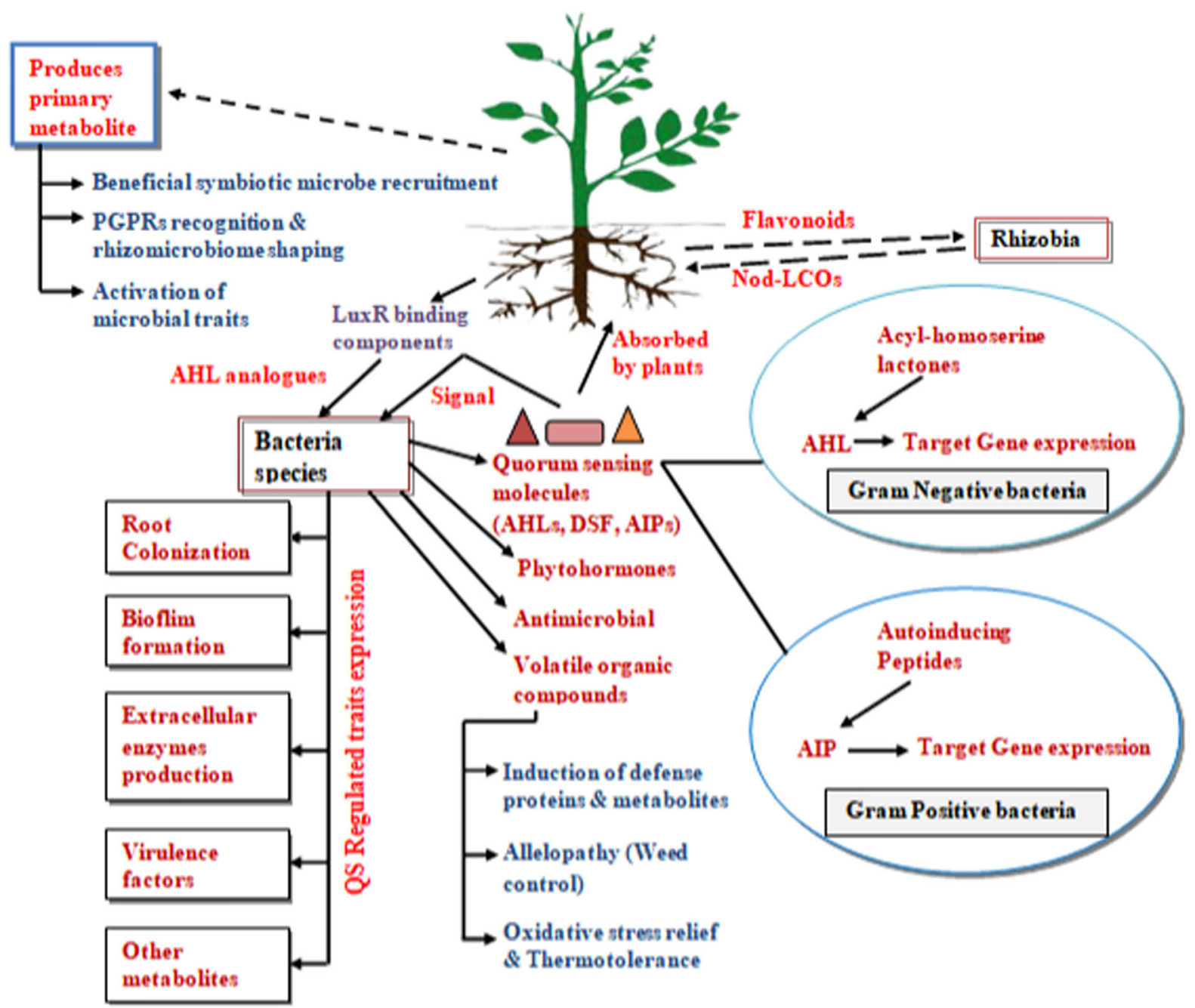

Fig. 5 Mechanisms and impacts of QS communication system used in different kinds of interactions between plants and microorganisms. Plant and microbial associations are accelerated by several chemical signals exchanged between them. Plant species exude a variety of chemical substances in the rhizosphere, in order to easily interact with their nearby soil microorganisms and these chemical compounds are also involved in attracting beneficial microbes, activation of several

are also highlighted. Despite recent knowledge about this matter, the application of flavonoids in agricultural production is still very restricted. After decades of study on flavonoids compounds, these ubiquitous dietary components continue to surprise with their bioactivity patterns. In the integrative knowledgebased perspective, basic research on flavonoids, particularly diet-incorporated flavonoids, might give important grounds for health care, proper nutrition, and risk evaluation. Future research should focus on microbial traits and the formation of mutualistic relationships in the rhizosphere. QS molecules are used by several rhizobacteria to colonies plant surfaces or plant-associated environments through quorum sensing-mediated expression of genes. Bacteria also produce phytohormones, anti-microbial compounds, volatiles to induce defense proteins, metabolites and promote the growth and development of plant species by reducing oxidative stress and allelopathic effects

analysing and characterizing specific flavonoid chemicals found in the examined plant sections. Further analysis and investigation are needed to understand the entire range of action of natural and/or artificially derived flavonoids. The current analysis also focuses on the chemicals and metabolites generated by microbes and plants in the establishment of a close relationship, contributing to an improvement in plant growth and the activation of plant defence against pathogenic agents. Investigating different microbial 
communities is a significant barrier for plant-microbe interactions research, as it is difficult to answer questions including what the basic features of a particular community are, how the community members interact with one another, and how the community members help plant species to survive under such situations. It has now been well established that the plants are capable of regulating the recruitment of different root microbes and choosing particular microbes for required purposes. There is also a significantly higher demand to understand how rootassociated microbes are attracted by plants. In addition, the function of quorum sensing-mediated signalling and some other signalling pathways in the rhizosphere region that lead to the maintenance and establishment of complex root microbiome requires to be examined. Recent diverse research innovations in the area of plant-microbe interactions may have an intense impact on agricultural productivity. Research on advantageous plant-microbe interactions in the rhizosphere will greatly improve our understanding of how these microbes influence the nutritional content of plant materials. Exploiting and utilizing these silently benefiting microbial species living in the plant rhizosphere region is still a challenging area of research. The recent discovery of many enzymes and associated genes are necessary for the transport and biosynthesis of different rhizosphere signalling molecules that allow us to begin experimenting with metabolic engineering to influence the rhizosphere microbiome (Mishra et al. 2021). The emergence of meta-omics technologies like metagenomics and metabolomics helps us to investigate the implications of these innovative engineering approaches in greater depth (Haskett et al. 2021). Modifications in the metabolism status of these crucial signalling molecules must be closely monitored. Nevertheless, rhizosphere metabolic engineering is probably to become an effective tool for optimizing crop plant efficiency by altering the rhizosphere community structures. Recent advancements in next-generation sequencing technology will offer us additional knowledge about the species affected by plant exudates, as well as aid in unravelling the interaction and perception processes involved. The critical issue is that modifying these plant metabolic networks by genetic engineering can affect other processes in plants. Flavonoids, for example, influence the transport of auxin, a key plant hormone. By utilizing this efficient and environmentally rhizosphere engineering method we can get improved advantageous impacts from PGPRbased inoculants, such as nutrient availability, mitigation of abiotic and biotic stress, and health of soil with environmental sustainability. Genetic modification can be performed to modulate plants' gene expressions in such a way that can produce elevated targeted flavonoids to colonize growth-promoting microbes in the rhizosphere. By that engineering, flavonoids can influence the rhizosphere, attracting more beneficial microbes and thereby enhancing crop productivity and soil quality. This approach can be readily applicable in field environments and requires no regulatory approval; this solution assures many advantages, ecological protection, and sustainability.

Acknowledgements The work was funded by extramural funding from the Science and Engineering Research Board (SERB, Project File No. SRG/2020/000586), Department of Science and Technology, Government of India, and University Grants Commission (UGC, sanction order no. F. 30-509/2020 (BSR)], India to Avishek Banik. Sagar Bag would like to acknowledge University Grants Commission (UGC), India for NET Junior Research Fellowship (Ref. No. 201610001623).

\section{Declarations}

Conflict of interest The authors declare that they have no conflict of interest.

\section{References}

Abedini D, Jaupitre S, Bouwmeester H, Dong L (2021) Metabolic interactions in beneficial microbe recruitment by plants. Curr Opin Biotechnol 70:241-247

Akiyama K, Matsuoka H, Hayashi H (2002) Isolation and identification of a phosphate deficiency-induced C-glycosylflavonoid that stimulates arbuscular mycorrhiza formation in melon roots. Mol Plant Microbe Interact 15(4):334-340

Bae J, Kim N, Shin Y, Kim SY, Kim YJ (2020) Activity of catechins and their applications. Biomed Dermato 4:1-10

Bag S, Mondal A, Banik A (2022) Exploring tea (Camellia sinensis) microbiome: insights into the functional characteristics and their impact on tea growth promotion. Microbiol Res 254:126890

Bag S, Mondal A, Majumder A, Banik A (2022) Tea and its phytochemicals: hidden health benefits and modulation of signaling cascade by phytochemicals. Food Chem 371:131098. https://doi.org/10.1016/j.foodchem.2021. 131098

Bakker MG, Manter DK, Sheflin AM, Weir TL, Vivanco JM (2012) Harnessing the rhizosphere microbiome through 
plant breeding and agricultural management. Plant Soil 360:1-13

Banasiak J, Jamruszka T, Murray J, Jasiński M (2021) A road map of plant membrane transporters in arbuscular mycorrhizal and legume-rhizobium symbioses. Plant Physiol. https://doi.org/10.1093/plphys/kiab280

Banik A, Mukhopadhaya SK, Dangar TK (2016) Characterization of $\mathrm{N}_{2}$-fixing plant growth promoting endophytic and epiphytic bacterial community of Indian cultivated and wild rice (Oryza spp.) genotypes. Planta 243:799-812

Banik A, Mukhopadhaya SK, Sahana A, Das D, Dangar TK (2016) Fluorescence resonance energy transfer (FRET)based technique for tracking of endophytic bacteria in rice roots. Biol Fertil Soils 52:277-282

Banik A, Chattopadhyay A, Ganguly S, Mukhopadhyay SK (2019) Characterization of a tea pest specific Bacillus thuringiensis and identification of its toxin by MALDITOF mass spectrometry. Ind Crop Prod 137:549-556

Basit A, Shah ST, Ullah I, Ullah I, Mohamed HI (2021) Microbial bioactive compounds produced by endophytes (bacteria and fungi) and their uses in plant health. Plant Growth-Promot Microbes Sustain Biotic Abiotic Stress Manag 285-318

Bhattacharya A, Sood P, Citovsky V (2010) The roles of plant phenolics in defence and communication during Agrobacterium and Rhizobium infection. Mol Plant Pathol 11:705-719

Biała-Leonhard W, Zanin L, Gottardi S, de Brito Francisco R, Venuti S, Valentinuzzi F, Mimmo T, Cesco S, Bassin B, Martinoia E, Pinton R (2021) Identification of an isoflavonoid transporter required for the nodule establishment of the Rhizobium-Fabaceae symbiotic interaction. Front Plant Sci 12:758213

Bido GDS, Ferrarese MDLL, Marchiosi R, Ferrarese-Filho O (2010) Naringenin inhibits the growth and stimulates the lignification of soybean root. Braz Arch Biol Technol 53:533-542

Bosse MA, da Silva MB, de Oliveira NGRM, de Araujo MA, Rodrigues C, de Azevedo JP, dos Reis AR (2021) Physiological impact of flavonoids on nodulation and ureide metabolism in legume plants. Plant Physiol Biochem 166:512-521

Braidot E, Zancani M, Petrussa E, Peresson C, Bertolini A, Patui S, Macrì F, Vianello A (2008) Transport and accumulation of flavonoids in grapevine (Vitis vinifera L.). Plant Signal Behav 3:626-632

Caetano-Anolles G, Crist-Estes DK, Bauer WD (1988) Chemotaxis of Rhizobium meliloti to the plant flavone luteolin requires functional nodulation genes. $\mathrm{J}$ Bacteriol 170:3164-3169

Carazzone C, Mascherpa D, Gazzani G, Papetti A (2013) Identification of phenolic constituents in red chicory salads (Cichorium intybus) by high-performance liquid chromatography with diode array detection and electrospray ionisation tandem mass spectrometry. Food Chem 138:1062-1071

Cavia-Saiz M, Busto MD, Pilar-Izquierdo MC, Ortega N, PerezMateos M, Muñiz P (2010) Antioxidant properties, radical scavenging activity and biomolecule protection capacity of flavonoid naringenin and its glycoside naringin: a comparative study. J Sci Food Agric 90:1238-1244
Cesco S, Neumann G, Tomasi N, Pinton R, Weisskopf L (2010) Release of plant-borne flavonoids into the rhizosphere and their role in plant nutrition. Plant Soil 329:1-25

Chalupowicz L, Barash I, Panijel M, Sessa G, Manulis-Sasson S (2009) Regulatory interactions between quorum-sensing, auxin, cytokinin, and the Hrp regulon in relation to gall formation and epiphytic fitness of Pantoea agglomeranspv. gypsophilae. Mol Plant-Microbe interact 22:849-856

Chandra R, Banik A (2021) Detoxification and bioconversion of arsenic and chromium. In: Nanobiotechnology. Elsevier, pp 253-270. https://doi.org/10.1016/B978-0-12-822878-4. 00016-X

Chaparro JM, Sheflin AM, Manter DK, Vivanco JM (2012) Manipulating the soil microbiome to increase soil health and plant fertility. Biol Fertil Soils 48:489-499

Compton KK, Hildreth SB, Helm RF, Scharf BE (2020) An updated perspective on Sinorhizobium meliloti chemotaxis to alfalfa flavonoids.Frontiers in microbiology 11

Cooper JE (2004) Multiple responses of rhizobia to flavonoids during legume root infection. Adv Bot Res 41:1-62

Cushnie TPT, Hamilton VES, Chapman DG, Taylor PW, Lamb AJ (2007) Aggregation of Staphylococcus aureus following treatment with the antibacterial flavonol galangin. J Appl Microbiol 103:1562-1567

Dakora FD, Phillips DA (2002) Root exudates as mediators of mineral acquisition in low-nutrient environments. In: Food security in nutrient-stressed environments: exploiting plants' genetic capabilities, pp 201-213

Davies FT, Calderón CM, Huaman Z (2005) Influence of arbuscular mycorrhizae indigenous to Peru and a flavonoid on growth, yield, and leaf elemental concentration of Yungay' potatoes. HortSci 40:381-385

Del Valle I, Webster TM, Cheng HY, Thies JE, Kessler A, Miller MK, Ball ZT, MacKenzie KR, Masiello CA, Silberg JJ, Lehmann J (2020) Soil organic matter attenuates the efficacy of flavonoid-based plant-microbe communication. Sci Adv 6:eaax8254

Djordjevic MA, Redmond JW, Batley M, Rolfe BG (1987) Clovers secrete specific phenolic compounds which either stimulate or repress nod gene expression in Rhizobium trifolii EMBO J 6:1173-1179

Edziri H, Mastouri M, MahjoubMA, Mighri Z, Mahjoub A, Verschaeve L (2012) Antibacterial, antifungal and cytotoxic activities of two flavonoids from Retama raetam flowers. Molecules 17:7284-7293

Fakhri S, Moradi SZ, Farzaei MH, Bishayee A (2020) Modulation of dysregulated cancer metabolism by plant secondary metabolites: a mechanistic review. Seminars in cancer biology. Academic Press

Farrar K, Bryant D, Cope-Selby N (2014) Understanding and engineering beneficial plant-microbe interactions: plant growth promotion in energy crops. Plant Biotechnol J 12:1193-1206

Feldman M, Santos J, Grenier D (2011) Comparative evaluation of two structurally related flavonoids, isoliquiritigenin and liquiritigenin, for their oral infection therapeutic potential. J Nat Prod 74:862-1867

Fernie AR (2019) Evolution: an early role for flavonoids in defense against oomycete infection. Curr Biol 29:R688R690 
Geoghegan F, Wong RWK, Rabie ABM (2010) Inhibitory effect of quercetin on periodontal pathogens in vitro. Phytother Res 24:817-820

Gomes B, Castro F, Santos R, Figueiredo P, Silva M, Vidal M, Ferreira I, Nunes J, Machado H, Gomes F (2021) Effect of quercetin on Mycorrhizal synthesis between Tuberborchii and Arbutusunedo L. In vitro plants. Microbiol Res 12(1):69-81

Goya-Jorge E, Jorge Rodríguez ME, Veitía MSI, Giner RM (2021) Plant occurring flavonoids as modulators of the aryl hydrocarbon receptor. Molecules 26(8):2315

Gupta R, Chakrabarty SK (2013) Gibberellic acid in plant: still a mystery unresolved. Plant Signal Behav 8:e25504

Gurni AA, Wagner ML (1982) Apigeninidin as a leucoderivative in Ephedra frustillata Phytochemistry 21:2428-2429

Haskett TL, Tkacz A, Poole PS (2021) Engineering rhizobacteria for sustainable agriculture. ISME J 15(4):949-964

Hassan S, Mathesius U (2012) The role of flavonoids in rootrhizosphere signalling: opportunities and challenges for improving plant-microbe interactions. J Exp Bot 63:3429-3444

Huang XF, Chaparro JM, Reardon KF, Zhang R, Shen Q, Vivanco JM (2014) Rhizosphere interactions: root exudates, microbes, and microbial communities. Botany 92(4):267-275

Ingle K, Padole D, VC K (2016) Secondary metabolites for plant growth promotion and plant protection. Adv Life Sci 5:10888-10891

Jain C, Khatana S, Vijayvergia R (2019) Bioactivity of secondary metabolites of various plants: a review. Int J Pharm Sci Res 10:494-498

Jalmi SK (2020) Rhizosphere signaling nurturing phyto-microbiome niche. J Soc Trop Plant Res 7:522-528

Johnston GAR, Chebib M, Duke RK, Fernandez SP, Hanrahan JR, Hinton T, Mewett KN (2009) Herbal products and GABA receptors. Encycl Neurosci 4:1095-1101

Kape RUDIGER, Parniske M, Brandt S, Werner D (1992) Isoliquiritigenin, a strong nod gene-and glyceollin resistance-inducing flavonoid from soybean root exudate. Appl Environ Microbiol 58:1705-1710

Kapoor B, Gulati M, Gupta R, Singh SK, Gupta M, Nabi A, Chawla PA (2021) A review on plant flavonoids as potential anticancer agents. Curr Org Chem 25(6):737-747

Kaur S, Sharma N, Kapoor P, Chunduri V, Pandey AK, Garg M (2021) Spotlight on the overlapping routes and partners for anthocyanin transport in plants. Physiol Plant 171:868-881

Khalid M, Bilal M, HUANG DF (2019) Role of flavonoids in plant interactions with the environment and against human pathogens - a review. J Integr Agric 18:211-230

Kong W, Zhao Y, Xing X, Ma X, Sun X, Yang M, Xiao X (2015) Antibacterial evaluation of flavonoid compounds against E. coli by microcalorimetry and chemometrics. Appl Microbiol Biotechnol 99:6049-6058

Kumar S, Pandey AK (2013) Chemistry and biological activities of flavonoids: an overview. Sci World J https://doi.org/10. $1155 / 2013 / 162750$

Laskowski RA, Swindells MB (2011) LigPlot+: multiple ligand-protein interaction diagrams for drug discovery. J Chem Inf Model 51:2778-2786

Lee GS, Kim ES, Cho SI, Kim JH, Choi G, Ju YS, Park SH, Jeong SI, Kim HJ (2010) Antibacterial and synergistic activity of prenylated chalcone isolated from the roots of Sophora flavescens. J Korean Soc Appl Biol Chem 53:290-296

Lira MA Jr, Nascimento LR, Fracetto GG (2015) Legume-rhizobia signal exchange: promiscuity and environmental effects. Front Microbiol 6:945. https://doi.org/10.3389/ fmicb.2015.00945

Liskova A, Samec M, Koklesova L, Samuel SM, Zhai K, AlIshaq RK, Abotaleb M, Nosal V, Kajo K, Ashrafizadeh M, Zarrabi A (2021) Flavonoids against the SARS-CoV-2 induced inflammatory storm. Biomed Pharmacother 138: 111430

Liu CW, Murray JD (2016) The role of flavonoids in nodulation host-range specificity: an update. Plants 5:33

Liu Y, Jiang X, Guan D, Zhou W, Ma M, Zhao B, Cao F, Li L, Li J (2017) Transcriptional analysis of genes involved in competitive nodulation in Bradyrhizobium diazoefficiens at the presence of soybean root exudates. Sci Rep 7(1):1-11

López-Bucio J, Millán-Godínez M, Méndez-Bravo A, Morquecho-Contreras A, Ramírez-Chávez E, MolinaTorres J, Pérez-Torres A, Higuchi M, Kakimoto T, Herrera-Estrella L (2007) Cytokinin receptors are involved in alkamide regulation of root and shoot development in Arabidopsis. Plant Physiol 145:1703-1713

Marinova K, Pourcel L, Weder B, Schwarz M, Barron D, Routaboul JM, Debeaujon I, Klein M (2007) The Arabidopsis MATE transporter TT12 acts as a vacuolar flavonoid/H+-antiporter active in proanthocyanidinaccumulating cells of the seed coat. Plant Cell 19:2023-2038

Maxwell CA, Hartwig UA, Joseph CM, Phillips DA (1989) A chalcone and two related flavonoids released from alfalfa roots induce nod genes of Rhizobium meliloti. Plant Physiol 91:842-847

Mbengue MD, Hervé C, Debellé F (2020) Nod factor signaling in symbiotic nodulation. Adv Bot Res 94:1-39

Mehmood A, Hussain A, Irshad M, Hamayun M, Iqbal A, Rahman H, Tawab A, Ahmad A, Ayaz S (2019) Cinnamic acid as an inhibitor of growth, flavonoids exudation and endophytic fungus colonization in maize root. Plant Physiol Biochem 135:61-68

Meneses N, Taboada H, Dunn MF, del Carmen Vargas M, Buchs N, Heller M (2017) The naringenin-induced exoproteome of Rhizobium etli CE3. Arch Microbiol 199:737-755

Michaeli S, Avin-Wittenberg T, Galili G (2014) Involvement of autophagy in the direct ER to vacuole protein trafficking route in plants. Front Plant Sci 5:134

Mierziak J, Kostyn K, Kulma A (2014) Flavonoids as important molecules of plant interactions with the environment. Molecules 19:16240-16265

Mishra M, Singh SK, Kumar A (2021) Microbial consortia: approaches in crop production and yield enhancement. In: Microbiome stimulants for crops. Woodhead Publishing, pp 293-303

Mitter B, Brader G, Afzal M, Compant S, Naveed M, Trognitz F, Sessitsch A (2013) Advances in elucidating beneficial interactions between plants, soil, and bacteria. Adv Agron 121:381-445 
Mohiuddin AK (2018) Secondary metabolism and therapeutic efficacy of medicinal plants. J Pharmaceut Biolog Sci 6:104-108

Morales-Quintana L, Ramos P (2021) A talk between flavonoids and hormones to reorient the growth of gymnosperms. Int $\mathrm{J}$ Mol Sci 22:12630

Morris GM, Goodsell DS, Halliday RS, Huey R, Hart WE, Belew RK, Olson AJ (1998) Automated docking using a Lamarckian genetic algorithm and an empirical binding free energy function. J Comput Chem 19:1639-1662

Nabavi SM, Samec D, Tomczyk M, Milella L, Russo D, Habtemariam S, Suntar I, Rastrelli L, Daglia M, Xiao J, Giampieri F (2020) Flavonoid biosynthetic pathways in plants: Versatile targets for metabolic engineering. Biotechnol Adv 38:107316

Nagata M, Yamamoto N, Miyamoto T, Shimomura A, Arima S, Hirsch AM, Suzuki A (2016) Enhanced hyphal growth of arbuscular mycorrhizae by root exudates derived from high R/FR treated Lotus japonicus. Plant Signal Behav 11:e1187356

Nakabayashi R, Mori T, Saito K (2014) Alternation of flavonoid accumulation under drought stress in Arabidopsis thaliana Plant Signal Behav 9:e29518

Neal AL, Ahmad S, Gordon-Weeks R, Ton J (2012) Benzoxazinoids in root exudates of maize attract Pseudomonas putida to the rhizosphere. PLoS ONE 7:e35498

$\mathrm{Ng}$ JLP, Hassan S, Truong TT, Hocart CH, Laffont C, Frugier F, Mathesius U (2015) Flavonoids and auxin transport inhibitors rescue symbiotic nodulation in the Medicago truncatula cytokinin perception mutant cre1. Plant Cell 27:2210-2226

Novák K, Chovanec P, SÏkrdleta V, KropaÂcÏovaÂA M, LisaÂ L, NeÏmcovaÂ M (2002) Effect of exogenous flavonoids on nodulation of pea. J Exp Bot 53(375):1735-1745

Ortiz-Castro R, López-Bucio J (2019) Phytostimulation and root architectural responses to quorum-sensing signals and related molecules from rhizobacteria. Plant Sci 284:135-142

Panche AN, Diwan AD, Chandra SR (2016) Flavonoids: an overview.J Nutr Sci 5:e47

Pang Z, Chen J, Wang T, Gao C, Li Z, Guo L, Xu J, Cheng Y (2021) Linking plant secondary metabolites and plant microbiomes: a review. Front Plant Sci 12:300

Pascale A, Proietti S, Pantelides IS, Stringlis IA (2020) Modulation of the root microbiome by plant molecules: the basis for targeted disease suppression and plant growth promotion. Front Plant Sci 10:1741

Peck MC, Fisher RF, Long SR (2006) Diverse flavonoids stimulate NodD1 binding to nod gene promoters in Sinorhizobium meliloti J Bacteriol 188(15):5417-5427

Pei Y, Siemann E, Tian B, Ding J (2020) Root flavonoids are related to enhanced AMF colonization of an invasive tree. AoB Plants 12:plaa002

Pérez-Montaño F, Guasch-Vidal B, González-Barroso S, López-Baena FJ, Cubo T, Ollero FJ, Gil-Serrano AM, Rodríguez-Carvajal M, Bellogín RA, Espuny MR (2011) Nodulation-gene-inducing flavonoids increase overall production of autoinducers and expression of $\mathrm{N}$-acyl homoserine lactone synthesis genes in rhizobia. Res Microbiol 162:715-723
Peters NK, Frost JW, Long SR (1986) A plant flavone, luteolin, induces expression of Rhizobium meliloti nodulation genes. Science 233:977-980

Pinedo I, Ledger T, Greve M, Poupin MJ (2015) )Burkholderia phytofirmans PsJN induces long-term metabolic and transcriptional changes involved in Arabidopsis thaliana salt tolerance. Front Plant Sci 6:466

Poustka F, Irani NG, Feller A, Lu Y, Pourcel L, Frame K, Grotewold E (2007) A trafficking pathway for anthocyanins overlaps with the endoplasmic reticulum-to-vacuole protein-sorting route in Arabidopsis and contributes to the formation of vacuolar inclusions. Plant Physiol 145:1323-1335

Rai A, Saito K, Yamazaki M (2017) Integrated omics analysis of specialized metabolism in medicinal plants. Plant $\mathrm{J}$ 90:764-787

Randhawa HK, Hundal KK, Ahirrao PN, Jachak SM, Nandanwar HS (2016) Efflux pump inhibitory activity of flavonoids isolated from Alpinia calcarata against methicillinresistant Staphylococcus aureus Biologia 71:484-493

Rao HSP (1991) Isoflavones from Flemingia vestita. Fitoterapia 63:458

Rayanoothala P, Divya M, Mahapatra S, Das S (2021) Microbial biofilm: formation, quorum sensing, and its applications in plant disease management. emerging trends in plant pathology. Springer, Singapore, pp 385-397

Saito K, Yonekura-Sakakibara K, Nakabayashi R, Higashi Y, Yamazaki M, Tohge T, Fernie AR (2013) The flavonoid biosynthetic pathway in Arabidopsis: structural and genetic diversity. Plant Physiol Biochem 72:21-34

Samanta A, Das G, Das SK (2011) Roles of flavonoids in plants. Carbon 100:12-35

Sarmiento-López LG, López-Meyer M, Sepúlveda-Jiménez G, Cárdenas L, Rodríguez-Monroy M (2021) Arbuscular mycorrhizal symbiosis in Stevia rebaudiana increases trichome development, flavonoid and phenolic compound accumulation. Biocatal Agric Biotechnol 31:101889

Scervino JM, Ponce MA, Erra-Bassells R, Bompadre J, Vierheilig H, Ocampo JA, Godeas A (2007) The effect of flavones and flavonols on colonization of tomato plants by arbuscular mycorrhizal fungi of the genera Gigaspora and Glomus Can J Microbiol 53:702-709

Shah A, Smith DL (2020) Flavonoids in agriculture: chemistry and roles in, biotic and abiotic stress responses, and microbial associations. Agronomy 10:1209

Shamala T, Thilini AP, Anuradha S, Kulasooriya SA, Seneviratne $G$ (2018) The effect of flavonoid naringenin coupled with the developed biofilm Azorhizobium caulinodansAspergillus spp. on increase in rice yields in conventionally and organically grown rice. Int J Plant Stu 1:1-6

Sharifi-Rad J, Quispe C, Shaheen S, El Haouari M, Azzini E, Butnariu M, Sarac I, Pentea M, Ramírez-Alarcón K, Martorell M, Kumar (2021) M Flavonoids as potential antiplatelet aggregation agents: from biochemistry to health promoting abilities. Crit Rev Food Sci Nutrhttps://doi.org/ 10.1080/10408398.2021.1924612

Sharifi R, Ryu CM (2018) Revisiting bacterial volatile-mediated plant growth promotion: lessons from the past and objectives for the future. Ann Bot 122:349-358 
Sharma A, Singh P, Sarmah BK, Nandi SP (2020) Quorum sensing: its role in microbial social networking. Res Microbiol 171(5-6):159-164

Singla P, Garg N (2017) Plant flavonoids: Key players in signaling, establishment, and regulation of rhizobial and mycorrhizal endosymbioses. Mycorrhiza-function, diversity, state of the art. Springer Cham, pp 133-176

Solopova A, van Tilburg AY, Foito A, Allwood JW, Stewart D, Kulakauskas S, Kuipers OP (2019) Engineering Lactococcus lactis for the production of unusual anthocyanins using tea as substrate. Metab Eng 54:160-169

Subramanian S, Stacey G, Yu O (2007) Distinct, crucial roles of flavonoids during legume nodulation. Trends Plant Sci 12:282-285

Sundaravarathan S, Kannaiyan S (2002) 11. Role of plant flavonoids as signal molecules to rhizobium. Biotechnol Biofertiliz, p 144

Sweetlove LJ, Fernie AR (2013) The spatial organization of metabolism within the plant cell. Annu Rev Plant Biol 64:723-746

Szoboszlay M, White-Monsant A, Moe LA (2016) The effect of root exudate 7,4'-dihydroxyflavone and naringenin on soil bacterial community structure. PLoS ONE 11:e0146555

Tajuddeen N, Sallau MS, Musa AM, Yahaya SM, Habila JD, Ismail AM (2016) A novel antimicrobial flavonoid from the stem bark of Commiphora pedunculata (Kotschy \& Peyr.) Engl. Nat Prod Res 30:1109-1115

Taneja I, Arora S, Rama Raju KS, Siddiqui N (2013) Disposition of pharmacologically active dietary isoflavones in biological systems. Curr Drug Metab 14:369-380

Tatsimo SJN, de Dieu Tamokou J, Havyarimana L, Csupor D, Forgo P, Hohmann J, Kuiate JR, Tane P (2012) Antimicrobial and antioxidant activity of kaempferol rhamnoside derivatives from Bryophyllum pinnatum BMC Res Notes 5:1-6

Tian B, Pei Y, Huang W, Ding J, Siemann E (2021) Increasing flavonoid concentrations in root exudates enhance associations between arbuscular mycorrhizal fungi and an invasive plant. ISME J 15:1919-1930

Tohge TR, Fernie A (2017) An overview of compounds derived from the shikimate and phenylpropanoid pathways and their medicinal importance. Mini Rev Med Chem 17:1013-1027

Tohge T, de Souza LP, Fernie AR (2017) Current understanding of the pathways of flavonoid biosynthesis in model and crop plants. J Exp Bot 68:4013-4028

Tomasi N, Weisskopf L, Renella G, Landi L, Pinton R, Varanini Z, Nannipieri P, Torrent J, Martinoia E, Cesco S (2008) Flavonoids of white lupin roots participate in phosphorus mobilization from soil. Soil Biol Biochem 40:1971-1974

Treutter D (2006) Significance of flavonoids in plant resistance: a review. Environ Chem Lett 4:147-157

Tsanova-Savova S, Ribarova F, Gerova M (2005) (+)-Catechin and (-)-epicatechin in Bulgarian fruits. J Food Compos Anal 18:691-698

Ulanowska K, Majchrzyk A, Moskot M, Jakóbkiewicz-Banecka J, Węgrzyn G (2007) Assessment of antibacterial effects of flavonoids by estimation of generation times in liquid bacterial cultures. Biologia 62:132-135

Vasavi HS, Arun AB, Rekha PD (2014) Anti-quorum sensing activity of Psidium guajava L. flavonoids against Chromobacterium violaceum and Pseudomonas aeruginosa PAO1. Microbiology and immunology 58:286-293

Walker L, Lagunas B, Gifford ML (2020) Determinants of host range specificity in legume-rhizobia symbiosis. Front Microbiol 11:3028

Wen L, Wu D, Jiang Y, Prasad KN, Lin S, Jiang G, He J, Zhao M, Luo W, Yang B (2014) Identification of flavonoids in litchi (Litchi chinensis Sonn.) leaf and evaluation of anticancer activities. J Funct Foods 6:555-563

Weston LA, Mathesius U (2014) Root exudation: the role of secondary metabolites, their localisation in roots and transport into the rhizosphere. Root Engineering. Springer, Berlin Heidelberg, pp 221-247

Weston LA, Ryan PR, Watt M (2012) Mechanisms for cellular transport and release of allelochemicals from plant roots into the rhizosphere. J Exp Bot 63:3445-3454

Wu T, He M, Zang X, Zhou Y, Qiu T, Pan S, Xu X (2013) A structure-activity relationship study of flavonoids as inhibitors of $E$. coli by membrane interaction effect. Biochim Biophys Acta (BBA)-Biomembr 1828:2751-2756

Xiao J (2017) Dietary flavonoid aglycones and their glycosides: which show better biological significance? Crit Rev Food Sci Nutr 57:1874-1905

Xiao J, Kai G (2012) A review of dietary polyphenol-plasma protein interactions: characterization, influence on the bioactivity, and structure-affinity relationship. Crit Rev Food Sci Nutr 52:85-101

Xia X, Ma C, Dong S, Xu Y, Gong Z (2017) Effects of nitrogen concentrations on nodulation and nitrogenase activity in dual root systems of soybean plants. Soil Sci Plant Nutr 63:470-482

Yang WY, Won TH, Ahn CH, Lee SH, Yang HC, Shin J, Oh KB (2015) )Streptococcus mutans sortase A inhibitory metabolites from the flowers of Sophora japonica. Bioorg Med Chem Lett 25:1394-1397

Yu P, He X, Baer M, Beirinckx S, Tian T, Moya YA, Zhang X, Deichmann M, Frey FP, Bresgen V, Li C (2021) Plant flavones enrich rhizosphere Oxalobacteraceae to improve maize performance under nitrogen deprivation. Nat Plants 7(4):481-499

Zhang H, Wang L, Deroles S, Bennett R, Davies K (2006) New insight into the structures and formation of anthocyanic vacuolar inclusions in flower petals. BMC Plant Biol $6: 1-14$

Zhao J (2015) Flavonoid transport mechanisms: how to go, and with whom. Trends Plant Sci 20:576-585

Zhao J, Dixon RA (2010) The 'ins' and 'outs' of flavonoid transport. Trends Plant Sci 15:72-80

Publisher's Note Springer Nature remains neutral with regard to jurisdictional claims in published maps and institutional affiliations. 